\section{Importância da gordura alimentar na prevenção e no controle de distúrbios metabólicos e da doença cardiovascular}

\author{
Importance of the dietary fat on the prevention and control \\ of metabolic disturbances and cardiovascular disease
}

Ana Maria Pita Lottenberg ${ }^{1}$

\section{RESUMO}

A Organização Mundial da Saúde (OMS) reiterou recentemente que o consumo de dietas inadequadas e a inatividade física estão entre os dez principais fatores de mortalidade. Diversos ensaios aleatorizados demonstram que intervenções alimentares adequadas podem diminuir ou prevenir significativamente o aparecimento de várias doenças crônicas não transmissíveis. Neste contexto, o papel da dieta vem sendo exaustivamente avaliado em estudos clínicos e epidemiológicos. Assim, já foi bem estabelecido na literatura que a quantidade e o tipo de gordura alimentar exercem influência direta sobre fatores de risco cardiovascular, tais como a concentração de lípides e de lipoproteínas plasmáticas, bem como sua associação a processos inflamatórios. Os ácidos graxos participam de complexos sistemas de sinalização intracelular, função que vem sendo bastante explorada. Os ácidos graxos poli-insaturados não somente influenciam a composição das membranas, metabolismo celular e sinais de tradução, mas também modulam a expressão de genes, regulando a atividade e a produção de diversos fatores de transcrição. A proposta deste artigo é rever tópicos relevantes referentes ao metabolismo de lípides e os relacionar a terapias nutricionais que possam contribuir para a prevenção e o tratamento de doenças associadas. Arq Bras Endocrinol Metab. 2009;53(5):595-607.

Descritores

Dieta; colesterol; ácidos graxos alimentares; $\omega$-3; dislipidemias; doença cardiovascular; inflamação; tratamento dietético

\begin{abstract}
The World Health Organization (WHO) has recently reinforced the fact that inadequate diets, along with physical inactivity, are among the ten main determinant factors of mortality. Several randomized trials demonstrated that dietary interventions may lower or even prevent the occurrence of several non-communicable diseases. In this context, the role of diet has been exhaustively evaluated in several clinical and epidemiological studies. Thus, it is well established in literature that the amount and type of dietary fat have a direct influence on cardiovascular risk factors, such as lipids and plasma lipoprotein concentration, as well as their association with inflammatory processes. Fatty acids also participate in complex intracellular signaling systems, a function which has been currently investigated. Dietary polyunsaturated fatty acids (PUFA) act not only by altering membrane lipid composition, cellular metabolism and signal transduction, but also modulating gene expression by regulating the activity and/or production of different nuclear transcription factors. The aim of this article is to review important topics regarding the lipids metabolism and correlate them with nutritional therapies that may contribute to the prevention and treatment of related diseases. Arq Bras Endocrinol Metab. 2009;53(5):595-607.
\end{abstract}

Keywords

Diet; cholesterol; dietary fatty acids; omega-3; dyslipidemia; cardiovascular disease; inflammation; dietary treatment
${ }^{1}$ Laboratório de Lípides do Hospital das Clínicas da Faculdade de Medicina da Universidade de São Paulo (HC-FMUSP), São Paulo, SP, Brasil

Correspondência para: Ana Maria Pita Lottenberg Av. Doutor Arnaldo, 455, 3ㅇandar, sala 3305 01246-000 - São Paulo, SP, Brasil amlottenberg@uol.com.br

Recebido em 8/Mai/2009 Aceito em 11/Jun/2009 


\section{INTRODUÇÃO}

doença cardiovascular é uma das principais causas de morbidade e mortalidade, e múltiplos estudos epidemiológicos associam a composição da dieta aos seus principais fatores de risco. A Organização Mundial da Saúde (OMS) reiterou recentemente que o consumo de dietas inadequadas, juntamente com a inatividade física, está entre os dez principais fatores determinantes de mortalidade (1).

As pesquisas iniciais sobre aterosclerose basearam-se quase totalmente na hipótese lipídica. Mesmo com o surgimento de novas teorias, como a oxidativa, estas foram colocadas dentro de um contexto que envolve o metabolismo de lípides, como a oxidação das partículas de LDL (2). Diversos ensaios aleatorizados demonstram que intervenções alimentares adequadas podem diminuir (3) ou prevenir significativamente o aparecimento de diversas doenças crônicas não transmissíveis (4-6). Neste contexto, o papel da dieta vem sendo exaustivamente avaliado em estudos clínicos e epidemiológicos. Já foi bem estabelecido na literatura que a quantidade e o tipo de gordura alimentar exercem influência direta sobre fatores de risco cardiovascular, tais como a concentração de lípides e de lipoproteínas plasmáticas. $\mathrm{O}$ estudo Interheart (7) identificou três padrões alimentares distintos após avaliar a dieta de indivíduos de 52 países, denominados, respectivamente, dieta oriental (rica em proteínas vegetais), dieta ocidental (rica em gordura) e dieta prudente (rica em frutas e hortaliças). Observou-se um aumento de risco para infarto agudo do miocárdio de aproximadamente $30 \%$ na população que segue a dieta ocidental. Associação inversa foi obtida com o consumo de dieta denominada prudente.

Serão abordados, neste artigo, aspectos relevantes no metabolismo de lípides que embasam terapias nutricionais empregadas para a prevenção e o tratamento de doenças associadas a distúrbios lipídicos.

\section{ASPECTOS DA CLASSIFICAÇÃO E METABOLIZAÇÃO DAS GORDURAS}

Os lípides estão envolvidos no abastecimento e no armazenamento de energia, são precursores da síntese de hormônios, componentes da bile e da membrana celular e participam de complexos sistemas de sinalização intracelular. Derivados de ácidos graxos, atuam na síntese de prostaglandinas, leucotrienos e tromboxanas.

Aproximadamente $98 \%$ da gordura dos alimentos se encontra na forma de triglicérides, formados por uma molécula de glicerol, esterificada a três ácidos graxos, denominados saturados, monoinsaturados, poli-insaturados e trans. A dieta nos países ocidentais fornece de $30 \%$ a $40 \%$ das calorias na forma de gordura e aproximadamente $300 \mathrm{mg}$ de colesterol, e apenas $\mathbf{5 0 \%}$ do colesterol presente no lúmen intestinal é absorvido. A gordura de origem alimentar e a endógena são transportadas no plasma por meio das lipoproteínas, constituídas por lípides neutros, como colesterol-éster e triglicérides, em seu núcleo hidrofóbico, além de vitaminas lipossolúveis. Os fosfolípides, o colesterol livre e as apolipoproteínas são transportados na sua superfície hidrofílica. As lipoproteínas são responsáveis pelo transporte dos lípides na circulação linfática, sanguínea e no interstício. Os ácidos graxos livres são transportados pela albumina.

As lipoproteínas classificam-se em quilomícrons, lipoproteínas de muito baixa densidade (VLDL), de densidade intermediária (IDL), de baixa densidade (LDL) e de alta densidade (HDL). No plasma, são continuamente remodeladas durante o trânsito no compartimento plasmático, em razão da ação de enzimas e de proteínas de transferência. O papel fundamental dos quilomícrons e das VLDL é transportar, respectivamente, os triglicérides alimentares e os de síntese hepática (gordura endógena). As LDL são as principais lipoproteínas transportadoras de colesterol proveniente do fígado para os tecidos periféricos. As HDL são responsáveis pela remoção do colesterol de tecidos periféricos e de outras lipoproteínas, enviando-os ao fígado, o que caracteriza o denominado "transporte reverso de colesterol" (TRC).

Os triglicérides alimentares são parcialmente hidrolisados pelas lipases gástrica, intestinal e pancreática, gerando ácidos graxos e monoglicerídeos, absorvidos nas vilosidades intestinais e reesterificados, formando di e triglicérides. Estes se ligam à apolipoproteína B48 e, juntamente com o colesterol da dieta, da bile e vitaminas lipossolúveis, são transportados através dos quilomícrons, formados nas células epiteliais do intestino delgado. Os quilomícrons são secretados na linfa mesentérica e entram na circulação sistêmica pelo ducto torácico. Os triglicérides dessas partículas são, então, hidrolisados pelas enzimas lipoproteína lipase periférica (LLP) e lipase hepática (LLH) (8). A LLP é uma glicoproteína presente nas células endoteliais voltada para a luz capilar e não necessita ser liberada para a circulação sistêmica para que esteja na sua forma ativa (9); seu cofator ativador é a apoC II. A LLH é produzida 
no hepatócito e se localiza no endotélio dos capilares sinusoides. Hidrolisa triglicérides e fosfolípides, mas sua ação preponderante é agir como fosfolipase sobre as partículas de HDL2, transformando-as em HDL3 e pré-beta HDL (10).

Com essas alterações, têm origem, no espaço vascular extra-hepático, os remanescentes de quilomícrons, rapidamente captados pelo fígado, via receptores. Os remanescentes de quilomícrons são reconhecidos preferencialmente pelos receptores de LDL (receptor B/E), que identificam a apoE, podendo também ser captados pelo receptor $\alpha 2$ - macroglobulina do fígado e LRPI (proteína análoga ao receptor de colesterol). Essas partículas possuem meia-vida de aproximadamente 30 minutos.

Os lípides captados pelo fígado são, em parte, secretados para a circulação sob a forma de VLDL. A estrutura da VLDL e sua composição em apolipoproteínas têm muita semelhança com os quilomícrons. As células hepáticas, comparadas aos enterócitos, produzem maior quantidade de apoB, que é incorporada às VLDL, e é crítica no processo de secreção da partícula.

Aproximadamente $75 \%$ dos triglicérides das VLDL são hidrolisados pela LLP e LLH e se transformam em remanescentes (IDL). Uma parte menor da IDL é captada pelo fígado e o restante transforma-se em LDL pela ação da LLH. Em condições normais, as LDL são responsáveis pelo transporte de $65 \%$ a $70 \%$ do conteúdo plasmático total de colesterol. A maior parte das LDL é removida da circulação pelo fígado e o restante, por tecidos extra-hepáticos. Estas se ligam a receptores celulares, resultando em um complexo LDL-receptor, que é internalizado e degradado. Dois terços das LDL circulantes são removidos via receptor $\mathrm{B} / \mathrm{E}$.

\section{Aterogenicidade das partículas de LDL}

As LDL em excesso na circulação participam da formação do ateroma, após serem modificadas por oxidação. Lesões ateroscleróticas iniciais contêm células espumosas ("foam cells") constituídas, em grande parte, por macrófagos repletos de colesterol esterificado. Pelo fato de a captação da LDL oxidada não regular a atividade dos receptores "scavengers", sua remoção contínua leva ao acúmulo de colesterol intracelular, o qual é reesterificado pela ACAT (acil colesterol aciltransferase) - enzima responsável pelo armazenamento do colesterol no citoplasma. Concentrações aumentadas de LDL elevam o risco cardiovascular, mas sabe-se que seu tamanho pode ser preditor ainda mais importante. Partículas de menor tamanho (LDL pequenas e densas) são mais suscetíveis à oxidação pelo fato de as moléculas de apoB estarem mais expostas ao meio aquoso. $\mathrm{O}$ aumento da quantidade da apoB é indicativo da presença de partículas pequenas de LDL, sendo sua concentração plasmática diretamente proporcional à quantidade de triglicérides.

\section{Regulação do colesterol celular}

A concentração plasmática de colesterol é regulada pelos receptores $\mathrm{B} / \mathrm{E}$. As apo $\mathrm{Bl} 00$ e apoE, presentes na superfície dessas partículas, interagem com os receptores e facilitam sua internalização. O aumento do conteúdo intracelular de colesterol induz menor síntese dos receptores de LDL. Concomitantemente, ocorre inibição da atividade da hidroxi-metil-glutaril: coenzima A redutase (HMGCoA redutase), enzima-chave na biossíntese do colesterol. O inverso ocorre em situações de baixa concentração de colesterol, mantendo-se, dessa forma, a concentração intracelular relativamente constante. O colesterol livre presente na célula é esterificado pela ACAT.

Existem duas formas de colesterol presentes nas lipoproteínas plasmáticas (colesteril-éster e livre), sendo que aproximadamente $20 \%$ a $30 \%$ encontram-se na forma livre e são transferidos rapidamente entre as diferentes lipoproteínas plasmáticas e entre células e lipoproteínas. A via mais significativa para sua excreção é o sistema hepatobiliar, na forma de colesterol ou de ácido biliar, este último sintetizado sob ação da enzima $7-\alpha$ hidroxilase. O colesterol é liberado das células por meio de três mecanismos: alteração na estrutura química (sob a forma de ácidos biliares e hormônios); secreção, acoplado a apolipoproteínas e fosfolípides; e transferência para lipoproteínas do plasma.

Com exceção dos órgãos produtores de hormônios esteroides, tecidos extra-hepáticos não catabolizam o colesterol. Consequentemente, é necessário um mecanismo de transporte reverso de colesterol para manter o equilíbrio tecidual, que permita sua excreção na bile. Esse movimento é essencial para prevenção de acúmulos de colesterol, como os que ocorrem na lesão aterosclerótica e nos xantomas característicos da hiperlipidemia.

\section{Transporte reverso de colesterol}

A principal partícula envolvida no TRC é a HDL, que possui três origens: hepática, intestinal e produto da metabolização de lipoproteínas, como quilomícrons e VLDL. O TRC inicia-se com a captação de colesterol 
livre das membranas plasmáticas por meio das pré- $\beta$ HDL, no espaço intravascular dos tecidos periféricos. Estas se transformam gradativamente em HDL3 e, sob ação da enzima LCAT, responsável pela esterificação do colesterol, as HDL tornam-se enriquecidas em colesterol éster e passam a ser denominadas HDL2.

A HDL pode transportar o colesterol diretamente ao fígado ou, de maneira indireta, que é a via preponderante, transferi-lo para as VLDL e LDL, pela ação da CETP (proteína de transferência de colesterol esterificado). As LDL enriquecidas com colesterol éster são captadas pelo fígado, via receptor específico, por mecanismo de endocitose.

\section{IMPLICAÇÕES DO CONSUMO DE COLESTEROL}

O colesterol, quimicamente um álcool, é encontrado somente nas gorduras de origem animal, quase totalmente na forma livre (não esterificado). Suas principais fontes alimentares são a gema de ovo, leite e derivados, carne bovina, pele de aves e miúdos. A homeostase do colesterol depende do balanço entre ingestão, absorção/excreção e síntese. Embora a relação entre o colesterol alimentar, a sua absorção, e o metabolismo de remanescente de quilomícrons e aterosclerose seja complexa, diversos aspectos já foram elucidados. Apesar de o mecanismo molecular da absorção dos esteróis não ser totalmente conhecido (11), sabe-se que a Niemann-Pick Cl Like 1 Protein (NPClLl) é a principal proteína na membrana da borda em escova responsável por essa captação. No interior do enterócito, a maior parte do colesterol é esterificada pela enzima acil colesterol acil transferase (ACAT2) e, posteriormente, incorporada aos quilomícrons na membrana basolateral, culminando na secreção dessas partículas para o sistema linfático. Pequena quantidade de colesterol não esterificado retorna ao lúmen intestinal por meio de transportadores específicos, ABCG5 e ABCG8 (12).

A dieta contribui pouco $(300 \mathrm{mg} /$ dia $)$ para a totalidade do colesterol presente no lúmen, sendo a bile a principal fonte $(800-1200 \mathrm{mg} /$ dia $)$ (13), razão pela qual o colesterol alimentar exerce menor influência sobre a colesterolemia. O alto consumo de colesterol eleva a colesterolemia e pode induzir a aterosclerose precoce. Apesar de o colesterol alimentar relacionar-se à elevação do colesterol plasmático, seu efeito é menor quando comparado a outras variáveis alimentares, como ingestão de ácidos graxos saturados e trans, ou mesmo ao consumo total de gordura.
A heterogeneidade na resposta da colesterolemia diante do consumo de colesterol é explicada por diferentes genótipos de apoE. Estudos mostram que indivíduos portadores do alelo $\mathrm{E} 4$ apresentam maior absorção de colesterol quando submetidos a uma dieta rica em colesterol, e o contrário ocorre com portadores do alelo E2 (14). Em geral, portadores do alelo E3 absorvem normalmente o colesterol da dieta e representam aproximadamente $50 \%$ da população.

\section{RELAÇÃO DOS ÁCIDOS GRAXOS ALIMENTARES COM RISCO CARDIOVASCULAR}

Embora os ácidos graxos alimentares induzam maior alteração nos lípides plasmáticos, há grande variabilidade na resposta, com explicação limitada. Provavelmente, com os avanços na nutrogenômica, será possível melhorar a compreensão acerca dos resultados de estudos clínicos e epidemiológicos envolvendo diferentes dietas.

A classificação dos ácidos graxos é fundamentada em quatro aspectos: número de duplas ligações; comprimento da cadeia de carbono; configuração das duplas ligações; e posição do ácido graxo na molécula de glicerol. As variações estruturais dos ácidos graxos implicam modulações distintas da concentração plasmática do colesterol das lipoproteínas.

\section{Ácidos graxos saturados}

Além das gorduras animais (carnes, leite e derivados), vegetais como coco e cacau também são fontes de ácidos graxos saturados. Uma importante característica física dessas gorduras é apresentar-se na forma sólida à temperatura ambiente. Classificam-se basicamente em ácidos graxos cadeia média (C8 e C10) de cadeia longa de carbono. Os primeiros são absorvidos na forma não esterificada, ligam-se à albumina e são transportados ao fígado, onde são rapidamente metabolizados. Pelo fato de não serem transportados nos quilomícrons, não elevam os lípides no plasma (15). Dessa forma, indivíduos hiperquilomicronêmicos poderiam utilizá-los na dieta em substituição aos ácidos graxos de cadeia longa, que são incorporados aos quilomícrons. Ácidos graxos de cadeia longa são o palmítico (Cl6:0), cuja principal fonte é o óleo de palma, o mirístico (C14:0), encontrado no leite e derivados, e o esteárico (C18:0), presente na gordura do cacau. Entre os ácidos graxos da dieta, o palmítico é o mais abundante.

Estudos metabólicos e epidemiológicos (16-19) demonstraram que o ácido palmítico eleva a concentração 
plasmática de colesterol e de LDL-C, quando comparado à gordura poli-insaturada. Algumas razões para esse efeito são:

1. Redução do mRNA de receptores hepáticos de LDL, ou da sua atividade (20), talvez por alteração no conteúdo de ácidos graxos das membranas, diminuindo, assim, o catabolismo das LDL (19). Além disso, encontrou-se menor expressão do "LDL receptor-related protein I", como mecanismo alternativo ou adicional para explicar a elevação da colesterolemia (20).

2. Aumento da atividade da ACAT hepática, induzindo o enriquecimento de colesterol éster em lipoproteínas ricas em apo B (21).

3. Aumento da trigliceridemia como resultado do estímulo da secreção hepática de lipoproteínas contendo apoB-100 (22). Esta ação da gordura saturada foi confirmada em células Hep G2 pelo aumento da expressão hepática de genes envolvidos na síntese hepática de lípides (20).

4. As moléculas de ácidos graxos saturados empilham-se de maneira coesa por possuírem cadeia retilínea de carbono. Essa forma de empacotamento aumenta a capacidade de transporte de colesterol das partículas de LDL (23).

Deve-se ressaltar, no entanto, que, embora apresente cadeia saturada de carbono, o ácido esteárico não eleva a colesterolemia (24). A explicação é que a desidrogenação desse ácido graxo é mais veloz do que o alongamento da cadeia, fazendo com que seja mais rapidamente convertido em oleico no fígado (16), por meio das dessaturases.

Aparentemente, o ácido mirístico apenas se alonga, sendo mais rapidamente incorporado a triglicérides celulares, o que o torna o mais importante ácido graxo na elevação da colesterolemia (25). Em comparação a outros ácidos graxos saturados, o ácido mirístico induz a elevação da colesterolemia. Apesar desse efeito, recente metanálise não relacionou o leite ao aumento do risco cardiovascular, embora tenha sido registrada forte associação entre ingestão de manteiga e queijo, tanto com a elevação de LDL-C como com maior prevalência da síndrome metabólica (26). Provavelmente, indivíduos que mantiveram o consumo de leite apresentam também o hábito de consumir outros alimentos saudáveis.

Um dos mais importantes estudos de intervenção alimentar foi conduzido na Finlândia por um período de 20 anos, mostrando-se eficiente na redução de doença cardiovascular. Os indivíduos foram orientados a re- duzir o consumo de gordura total de $38 \%$ para $34 \%$ e de ácidos graxos saturados de $21 \%$ para $16 \%$, além de aumentar o volume de ingestão de frutas e vegetais (27). Na mesma linha, o Nurse's Health Study, envolvendo 80.082 mulheres acompanhadas por 14 anos, mostrou que a cada $5 \%$ de diminuição de calorias provenientes de gordura saturada havia $17 \%$ de queda no risco para doença cardiovascular (28).

\section{Ácidos graxos insaturados}

A classificação dos ácidos graxos insaturados baseia-se no número de duplas ligações. Denominados mono ou poli-insaturados, eles pertencem a diferentes séries, definidas pela localização da primeira dupla ligação na cadeia de carbono a partir do terminal metila, identificada pela letra $\omega$. Dessa forma, esses ácidos graxos são classificados em série $\omega-3, \omega-6$ e $\omega$-9.

O ácido oleico (C18:1), série $\omega$-9, é o mais frequentemente encontrado na natureza, sendo as principais fontes o óleo de oliva e canola ("Canadian oil"). No processo de produção do óleo de canola, extraído de uma gramínea ( "rapessed"), é eliminado o ácido erúcico (C22:1), série $\omega-9$, indesejável pelo sabor e por produzir miopatia. No Brasil, essa gramínea é cultivada em grande escala.

O poli-insaturado mais abundante, pertencente à série $\omega-6$, é o linoleico (Cl8:2), seguido do araquidônico (C20:4), presentes principalmente nos óleos de milho e girassol. As principais fontes de linolênico, série $\omega-3$, são a linhaça, soja e canola. Os ácidos graxos linoleico e linolênico são essenciais ao homem, pois as células dos mamíferos não têm a capacidade de inserir uma dupla ligação (dessaturar) antes do carbono 9 da cadeia dos ácidos graxos.

Os ácidos graxos eicosapentenoico (C20:5) e docosa-hexenoico (C22:6), série $\omega$-3, são encontrados na gordura dos peixes de águas frias e profundas. Não são essenciais aos humanos, pelo fato de serem sintetizados a partir do ácido linoleico.

Foram descritas diversas ações dos ácidos graxos poli-insaturados na modulação de vias que poderiam influenciar a colesterolemia: 1) diminuição da produção hepática de VLDL, precursora da LDL, tanto por maior catabolismo hepático desse ácido graxo nos peroxissomos, quanto por interferência com receptores nucleares; 2) aumento da fluidez das membranas do hepatócito, alterando a atividade dos receptores de LDL (29), e da quantidade de receptores hepáticos $\mathrm{B} / \mathrm{E}(30)$. Esse processo ocorre provavelmente em ra- 
zão da alta afinidade desses ácidos graxos com a ACAT, multiplicando o conteúdo celular de colesterol éster, condição que induz a síntese do receptor B/E (31). Estudo mostrou que os ácidos graxos poli-insaturados não aumentaram o mRNA para receptor de LDL, indicando que a regulação ocorreu em nível pós-traducional, em razão da abundância da proteína do receptor. 3 ) mudança na estrutura espacial das LDL, decorrente do fato de as moléculas poli-insaturadas dos fosfolípides apresentarem configuração cis, ocupando mais espaço na lipoproteína e, portanto, restringindo o volume disponível dessa partícula para transportar colesterol (23). É importante lembrar que os poli-insaturados de configuração trans não têm essa propriedade, pois apresentam cadeia retilínea de carbono, comportando-se como a gordura saturada; 4) formação de LDL com menor conteúdo de colesterol éster, por diminuir sua transferência da HDL para VLDL mediada pela CETP (32); 5 ) redução da trigliceridemia, pelo fato de estimularem a hidrólise de apo B-100 que ocorre após o retículoendoplasmático (33).

Os ácidos graxos poli-insaturados modulam diversos genes envolvidos nos processos oxidativos, aumentando, por exemplo, a expressão de PPARs (peroxisome proliferator-activated receptors), e bloqueiam aqueles relacionados com lipogênese. Os SREBP (sterol regulatory element-binding proteins) são fatores de transcrição ligados às membranas que induzem síntese de ácidos graxos e sua expressão é diminuída com a gordura poliinsaturada. O seu maior efeito inibitório foi sobre a expressão de SREBP-la e SREBP-lc (34).

Alguns estudos mostraram efeitos deletérios dos ácidos graxos poli-insaturados da série $\omega$ - 6 quando consumidos em grande quantidade, como provocar diminuição do HDL (35) e aumentar a suscetibilidade das LDL à oxidação (36). Em razão desses achados, alguns autores mostraram um potencial efeito aterogênico dos ácidos graxos, chegando a sugerir redução do seu consumo. No entanto, tais resultados devem ser analisados com cautela, visto que se sabe, a partir de diversos estudos populacionais $(1,28)$, que seu consumo relacionase à redução de doença coronariana. Recentemente, $\mathrm{o}$ Comitê de Nutrição da American Heart Association, revendo as evidências sobre $\omega-6$ e risco cardiovascular, reforçou que seu consumo deve ser estimulado (37).

Com relação ao ácido oleico, observou-se que, comparativamente à gordura saturada, reduz a concentração plasmática de LDL-C e não provoca oxidação das LDL (38). Uma das possíveis razões pelas quais o ácido oleico não eleva o LDL-C é o fato de ser um melhor substrato para a ACAT no fígado. Portanto, o excesso de colesterol na forma livre é rapidamente esterificado, não induzindo a supressão de receptores de LDL (39). Além disso, o oleico induz menor síntese endógena de colesterol, quando comparado a ácidos graxos poli-insaturados (40).

Está bem documentado que populações do Mediterrâneo, reconhecidas pelo alto consumo de ácido oleico, apresentam menor prevalência de obesidade, síndrome metabólica, diabetes tipo 2 e eventos cardiovasculares (4). Convém assinalar, no entanto, que a prevenção dessas doenças não pode ser atribuída exclusivamente ao consumo de azeite de oliva (41), mas também a outros alimentos utilizados por tais povos. Apesar de não haver um único padrão alimentar em razão de diversidades culturais, produtos como grãos integrais, frutas, peixes e hortaliças fazem parte da dieta em toda a região.

\section{Ácidos graxos trans}

São isômeros geométricos de ácidos graxos cis, apresentando a mesma forma molecular, mas diferenciando-se na sua estrutura. Na dupla ligação trans, os dois átomos de hidrogênio ligados aos de carbono estão localizados em lados opostos da cadeia carbônica, formando molécula linear, mais rígida, semelhante à de um ácido graxo saturado. A configuração trans do ácido oleico é o ácido elaídico, originado principalmente no processo de hidrogenação industrial da gordura poli-insaturada. Os ácidos graxos trans podem ser sintetizados a partir de fermentação de bactérias em ruminantes, sendo encontrados em quantidades insignificantes na carne e no leite (42). São produzidos também por meio de hidrogenação catalítica, processo que se aplica aos óleos vegetais líquidos à temperatura ambiente, com o objetivo de conferir consistência de semissólida a sólida. A principal fonte de gordura trans na dieta é a vegetal hidrogenada, utilizada industrialmente na produção de biscoitos, bolachas recheadas, empanados tipo nuggets, sorvetes cremosos, tortas e alimentos comercializados em restaurantes "fast-food". Embora esses ácidos graxos sejam abundantes nas margarinas duras, representam apenas $10 \%$ do consumo de gorduras trans, sendo os alimentos industrializados a maior fonte.

Os ácidos graxos trans elevam a colesterolemia de maneira similar aos saturados, apresentando efeito adverso adicional de redução do HDL provavelmente por induzir aumento do catabolismo da apo Al e maior 
atividade da CETP (43). Reduzem as HDL2, subfração mais sensível a modificações alimentares. Com relação à influência desses ácidos graxos da dieta sobre a capacidade da HDL em retirar colesterol de macrófagos, demonstrou-se que a gordura trans não alterou a eficiência dessa partícula em comparação a ácidos graxos poli-insaturados ou saturados (44). Portanto, sua ação deletéria não pode ser explicada pela participação na primeira etapa do transporte reverso de colesterol. É importante salientar que, neste estudo, realizado com indivíduos normais, utilizou-se quantidade regular de gordura (30\% das calorias). Outras possíveis ações aterogênicas desses ácidos graxos, relativas ao efluxo de colesterol das artérias, necessitam ser mais exploradas.

Os ácidos graxos trans diminuem a expressão das proteínas estimuladoras de acilação (ASP) e aumentam a quantidade de ácidos graxos livres na circulação. Essas proteínas relacionam-se com a captação de triglicérides pelo adipócito e sua redistribuição. Interagem com membranas celulares, estimulando a diacilglicerol que, via proteína $\mathrm{C}$ quinase, regula a síntese de triglicérides. Além disso, as ASP agem sobre a captação da glicose independentemente da ação da insulina. Assim, sua diminuição no plasma, provocada pelos ácidos graxos trans, poderia contribuir indiretamente para resistência periférica à ação da insulina (45). Essas substâncias ainda elevam o risco de doença cardiovascular por sua ação sobre fatores de risco e também por ação direta no endotélio. Provocam lesão e morte do endotélio por induzirem apoptose em células humanas por ativação da via das caspases (46).

\section{Ácidos graxos $\omega-3$}

Ácidos graxos da série $\omega$-3 $-\alpha$-linolênico (ALA), eicosapentaenoico (EPA) e docosa-hexaenoico (DHA) apresentam o maior comprimento de cadeia e são altamente poli-insaturados. $\mathrm{O}$ interesse por eles surgiu em 1970, pela observação de que esquimós da Groenlândia apresentavam baixa incidência de doença coronariana, maior tempo de sangramento e menor concentração de lípides e lipoproteínas plasmáticas. Verificou-se que as alterações não eram relacionadas a fatores genéticos, mas ambientais, provavelmente relacionados ao alto consumo de peixe, hábito diário daquela população. Os resultados foram confirmados posteriormente em estudo do tipo coorte realizado no Japão (47).

Os ácidos graxos $\omega$-3 relacionam-se à redução moderada de trigliceridemia por diminuírem a atividade da diacilglicerolaciltransferase, enzima implicada na síntese hepática de triglicérides (48), diminuindo a secreção hepática de VLDL (49). Além disso, pelo fato de estarem envolvidos em importantes vias regulatórias transcricionais, aumentam o PPAR- $\alpha$ (peroxisome proliferator-activated receptor alpha), envolvido na síntese da lipoproteína lipase (50). Atuam no núcleo, na regulação de genes envolvidos na lipogênese, conjuntamente com receptores nucleares e fatores de transcrição, incluindo o PPAR, HNF (bepatocyte nuclear factor- $4 \alpha$ ), LXR (liver X receptor) e NF kappa B ( $n u$ clear factor-kappa B) (51). Dessa forma, aumentam a oxidação de ácidos graxos por meio de ativação do PPAR- $\alpha$ ou por reduzir a atividade do SREBP. Ativam, também, o PPAR- $\gamma$, exacerbando a oxidação de ácidos graxos e diminuindo a resistência à insulina (52). Suprimem o ChREBP (carbohydrate regulatory element binding protein), interferindo no metabolismo hepático da glicose (50).

Com relação ao efeito do $\omega$-3 no controle glicêmico, metanálise incluindo 21 estudos revelou que a suplementação desses ácidos graxos não foi associada à melhora na hemoglobina glicada (53).

Ácidos graxos das séries $\omega$ - 3 e $\omega$ - 6 são precursores da síntese de prostaglandinas e leucotrienos, envolvidos em processos de coagulação e inflamação, respectivamente (Figura 1). Os $\omega-6$ participam da via inflamatória e os $\omega$-3 ativam a via anti-inflamatória. A produção de eicosanoides pelas plaquetas e células da parede vascular modula processos fisiológicos, incluindo complacência arterial, fluidez, agregação plaquetária e inflamação, minimizando o risco de aterosclerose. $\mathrm{O}$ balanço entre a produção das prostaglandinas é essencial à prevenção de complicações trombóticas.

Por meio das dessaturases, o ácido linoleico é convertido a araquidônico e o ácido alfa-linolênico, a eicosapentaenoico. $\mathrm{O}$ ácido araquidônico é o precursor das prostaglandinas E2 (PGE2), leucotrienos B4 (LTB4), os quais são importantes eicosanoides pró-inflamatórios, e a tromboxana A2 (TXA2), potente vasoconstritor e agregador plaquetário. Na outra via, o ácido eicosapentaenoico é convertido em prostaglandinas $\mathrm{E}_{3}$ $\left(\mathrm{PGE}_{3}\right.$ ), leucotrieno B5 (LTB5) e a tromboxana A3 (TXA3), com ações potencialmente anti-inflamatórias e antitrombóticas. Dessa forma, os $\omega-3$ e $\omega-6$ competem por enzimas em vias metabólicas comuns. O ácido araquidônico é também precursor da síntese de epóxidos, potentes vasoconstritores, e responsáveis pelo aumento do depósito de cálcio nas células endoteliais. 
Em suma, a ingestão adequada das duas séries de ácidos graxos ( $\omega$-3 e $\omega$-6) garante o equilíbrio necessário ao controle dos processos de coagulação e de inflamação (54) (Figura 1).
(LTB4)

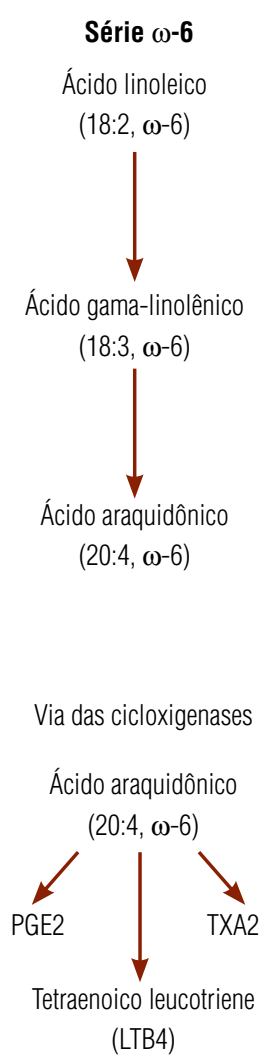

Série $\omega-3$

Ácido alfa-linolênico

$(18: 3, \omega-3)$

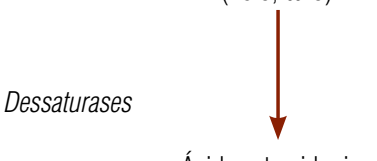

Ácido estearidonico

$(18: 4, \omega-3)$

Elongases

$$
\begin{gathered}
(20: 5, \omega-3) \\
\text { Ácido docosa-hexaenoico }
\end{gathered}
$$$$
\text { Ácido eicosapentaenóico }
$$

$(22: 6, \omega-3)$

Via das lipoxigenases

Ácido eicosapentaenoico

$(20: 5, \omega-3)$

Ácido docosa-hexaenoico $(22: 6, \omega-3)$

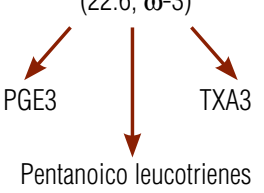

(LTB5)
Figura 1. Efeitos dos ácidos graxos araquidônico e eicosapentanóico sobre a ativação/inibição da produção de mediadores inflamatórios. Modificado de: James MJ, Gibson RA, Cleland LG. Dietary polyunsaturated fatty acids and inflammatory mediator production. Am J Clin Nutr. 2000;71(1 Suppl):343S-8S.

Entre os principais estudos de intervenção com ácidos graxos $\omega-3$, destaca-se o Lyon Diet Heart Study, no qual 200 indivíduos foram orientados a aumentar o consumo de fibras e de $\omega$-3 (ácido $\alpha$-linolênico). Embora não tenha havido alteração na colesterolemia, ocorreram diminuição dos eventos cardiovasculares e mortalidade. Porém, na investigação não foi possível atribuir o benefício apenas aos $\omega-3$, pelo fato de os indivíduos terem alterado o hábito alimentar de modo benéfico (55).

O GISSI, conduzido na Itália, foi um estudo de prevenção secundária de eventos cardiovasculares no qual se compararam os efeitos de ingestão diária de cápsulas de $\omega$-3, vitamina E ou ambos. Verificou-se que apenas o $\omega-3$ conferiu proteção cardiovascular, obtida em tempo relativamente curto e sem alterar os lípides no plasma (56).
Recomenda-se o consumo diário de aproximadamente $1,0 \mathrm{~g}$ de $\omega$-3 na dieta, sendo que a ingestão moderada de óleo de soja ou canola fornece as quantidades necessárias desse ácido graxo, não sendo necessária sua suplementação na dieta. Com relação à manutenção da proporção de $\omega$-6 e $\omega$-3 na prevenção cardiovascular, o estudo europeu OPTLIP reafirmou a importância do consumo de $\omega$-3 e a irrelevância de se estabelecer qualquer proporção entre $\omega-6$ e $\omega-3$ na dieta (57).

\section{Fitoesteróis}

Os fitoesteróis são encontrados naturalmente nos vegetais, enquanto os estanóis são produzidos artificialmente por hidrogenação do esterol. O sitosterol é o mais abundante nos alimentos, seguido do campesterol e stigmasterol. Estruturalmente, os fitoesteróis diferem do colesterol por possuírem um grupo metil ou etil no carbono 24 ou uma dupla ligação na sua cadeia (58). As principais fontes de fitoesteróis na dieta são os grãos, os óleos e as margarinas; a ingestão média diária de fitoesteróis varia entre 200 e $400 \mathrm{mg}$, mas apenas 1\% é absorvido (59).

Os mecanismos de ação pelos quais os fitoesteróis reduzem a absorção do colesterol ainda não são completamente conhecidos. Eles interferem na solubilização e incorporação do colesterol dentro da micela; competem com o colesterol, pois possuem maior afinidade físico-química com a micela, permanecendo mais tempo em seu interior, o que desloca o colesterol para fora desta estrutura e diminui sua absorção pelo enterócito (60). As micelas aproximam-se da borda em escova das células intestinais. O colesterol atravessa a camada aquosa e é absorvido pelo enterócito (61). Após captação pela NPClLl no enterócito, os fitoesteróis retornam ao lúmen através das proteínas transportadoras ABCG5 e ABCG8. Uma ínfima parte pode ser esterificada pela ACAT2, transportada por lipoproteínas e excretada pela bile $(58,62)$.

Para serem utilizados em preparações alimentícias, os fitoesteróis são esterificados com ácidos graxos derivados de óleos vegetais, sendo, então, transformados de sua forma cristalina, que é pouco solúvel em decorrência do elevado ponto de fusão, para a forma solúvel em gordura, mais facilmente incorporada aos alimentos. Em humanos, $2 \mathrm{~g} /$ dia de fitoesteróis são necessários para redução significativa da colesterolemia, mas as concentrações de HDL-C e triglicérides não se alteram $(63,64)$. Indivíduos hipercolesterolêmicos moderados podem se beneficiar de seu consumo diário, pois redu- 
zem, em média, 12\% o LDL-C. No entanto, a grande variabilidade dessa resposta deve ser considerada.

\section{ÁCIDOS GRAXOS ALIMENTARES E RELAÇÃO COM INFLAMAÇÃO}

Desde a década de 1950, sabe-se que a gordura alimentar aumenta o risco cardiovascular e que o consumo superior a $30 \%$ das calorias na forma de gordura relaciona-se à maior incidência de aterosclerose. $\mathrm{Na}$ mesma época, estabeleceu-se a forte associação entre obesidade, diabetes e inflamação. Demonstrou-se, posteriormente, que metabolismo e imunidade são condições interdependentes e que excesso de ingestão alimentar induz maior risco para doenças inflamatórias. Assim, o consumo adequado de nutrientes é fundamental para se preservar a função imunológica.

Obesidade, diabetes melito e dislipidemia são condições pró-aterogênicas e se sabe que tanto macrófagos como adipócitos participam na fisiopatogênese dessas doenças. Em razão de essas células terem origem embrionária comum, são capazes, em situações especiais, de produzir os mesmos componentes (65). Em condições normais, os adipócitos armazenam lípides e regulam a homeostase metabólica, enquanto os macrófagos relacionam-se com a resposta inflamatória. $\mathrm{Na}$ obesidade, ocorre sobreposição das vias metabólicas e inflamatórias. Assim, a expressão de genes torna-se similar em ambas as células. Os macrófagos passam a expressar proteínas normalmente produzidas pelo adipócito, como as FABP (proteínas transportadoras de ácidos graxos), com simultânea produção nos macrófagos, de citoquinas inflamatórias, como o TNF- $\alpha$, interleucina-6, e MCP (proteínas quimiotáticas de monócitos). As FABP modulam o acúmulo de lípides no adipócito e de colesterol no macrófago (66).

Estudo com animais LDL R-/-, transgênicos para o gene agouti, submetidos a uma dieta hiperlipídica ou normal, revelou que ambos os grupos apresentaram grande infiltração de macrófagos no tecido adiposo. $\mathrm{O}$ aumento foi mais pronunciado no grupo que recebeu dieta rica em gordura (67), exacerbando, portanto, o processo inflamatório. Em outro estudo, Nappo e cols. (68) verificaram que dieta rica em gordura aumentou moléculas de adesão vascular (VCAM-1) e intercelular (ICAM), interleucina-6 e TNF- $\alpha$ e esse efeito foi exacerbado em indivíduos diabéticos. Houve também maior expressão de TNF- $\alpha$ em tecido adiposo retroperitoneal com dieta hiperlipídica. Já está bem estabelecida na literatura a ação do TNF- $\alpha$ na resistência à insulina, indução da síntese de VCAM, ICAM e selectina-e, na redução da disponibilidade de eNOS, além de induzir apoptose da célula endotelial.

Os lípides participam, concomitantemente, da regulação de vias metabólicas e de processos inflamatórios. Por meio das FABP, ativam quinases intracelulares, como "inhibitor-kappa B quinase" (IKK), "c-jun $\mathrm{N}$-terminal kinase”(JNK) e proteína C quinase (PKC), que também podem ser ativadas através do estresse do retículo endoplasmático. Uma vez ativadas, as quinases impedem a sinalização do receptor de insulina e, simultaneamente, induzem a produção de biomarcadores inflamatórios, como o TNF- $\alpha$ e interleucinas, pela ativação do "nuclear-factor NF-kappa B". Além da sua ação na via inflamatória, os lípides ativam o PPAR e o LXR, ambos envolvidos no transporte e na síntese de nutrientes, bem como do efluxo de colesterol do macrófago (66).

Com relação ao efeito específico dos ácidos graxos sobre inflamação, diversos estudos têm encontrado forte associação da ingestão de gordura trans e saturada com a síntese de biomarcadores inflamatórios em comparação a ácidos graxos poli-insaturados (69). Em comparação ao ácido oleico, o consumo de ambos aumentou a concentração plasmática de interleucina-6, proteína $\mathrm{C}$ reativa selectina-e. Estudo epidemiológico, conduzido em indivíduos com sobrepeso, demonstrou aumento de interleucina- 6 com gordura saturada (70).

Recentemente, foi publicado um documento da American Heart Association (72) que discute as futuras implicações da redução de gordura trans nos produtos industrializados, com concomitante aumento de ácidos graxos saturados. A maior preocupação do comitê é o fato de as indústrias enriquecerem seus produtos com gorduras saturadas em vez de utilizarem maiores proporções de poli-insaturados. Realmente, o alto consumo de ácidos graxos saturados relaciona-se à lipotoxicidade de diversos órgãos e pode aumentar o risco para diabetes e doenças cardiovasculares $(72) \mathrm{em}$ consequência de sua forte relação com inflamação e resistência à insulina.

\section{RECOMENDAÇÃO DIETÉTICA PARA 0 TRATAMENTO DAS DISLIPIDEMIAS}

Comparando-se a última diretriz do NCEP-ATPIII (73) à anterior, verifica-se que houve inclusão do Escore de Framinghan, alteração das modificações nos valores de referência de lípides e de lipoproteínas plasmáticas 
e na distribuição de nutrientes da dieta, intensificando implementação nutricional e aspectos relacionados à síndrome metabólica. A principal ênfase desse consenso para o tratamento das dislipidemias é priorizar hábitos mais saudáveis no estilo de vida, o que inclui adequação da dieta, prática de atividade física e mudança comportamental.

Não há consenso até o momento com relação à quantidade máxima de gordura trans permitida na dieta. No entanto, preconiza-se o menor consumo possível desses ácidos graxos.

Da mesma forma que em outras questões científicas, níveis de evidência para a alteração de nutrientes na dieta também foram estratificados segundo a tabela 1 .

\begin{tabular}{cl}
\hline Tabela 1. Classificação do nível e impacto de envidência \\
\hline Nível de evidência & Descrição do tipo de evidência \\
\hline A & $\begin{array}{l}\text { Ensaios clínicos randomizados, de maior número } \\
\text { de participantes e adequadamente controlados }\end{array}$ \\
B & Pequenos ensaios controlados \\
C & Estudos observacionais e metabólicos \\
D & Experiência clínica \\
\hline Impacto da evidência & Descrição do impacto da evidência \\
\hline 1 & Evidência muito forte \\
2 & Evidência moderadamente forte \\
3 & Tendência forte \\
\hline
\end{tabular}

Segundo esses critérios, o conhecimento sobre as gorduras e alguns nutrientes a elas relacionados está resumido a seguir:

1. Ácidos graxos saturados

- Aumento da incidência de doença coronariana (C2).

- Redução da ingestão de gordura saturada diminuindo risco para doença coronariana $(\mathrm{Al}, \mathrm{Bl})$.

2. Ácidos graxos trans

- Elevam o LDL-C (A2).

- Estudos prospectivos apoiam associação entre consumo de trans e incidência de doença coronariana $(\mathrm{C} 2)$.

\section{Colesterol}

- Alto consumo de colesterol aumenta o LDL-C (A2, B1).

- Redução da ingestão de colesterol diminui o LDL na maioria dos indivíduos (Al, Bl).

4. Ácidos graxos monoinsaturados

- Reduzem o LDL-C em relação aos ácidos graxos saturados (A2, B2).
- Não diminuem o HDL-C e não aumentam os triglicérides (A2, B2).

- Dieta rica em monoinsaturados provenientes de frutas, vegetais e grãos integrais e com baixo teor de gordura é associada à diminuição do risco cardiovascular $(\mathrm{Cl})$.

\section{5. Ácidos graxos poli-insaturados}

- Ácido linoleico em substituição aos ácidos graxos saturados reduz o LDL-C (Al, Bl).

- Podem causar pequena redução do HDL-C em comparação aos ácidos graxos monoinsaturados (B2).

- Estudos clínicos controlados mostram que a substituição de gordura saturada por poli-insaturada reduz o risco cardiovascular (A2, B2).

\section{Estanóis (esteróis)}

- Ingestão de 2-3 g/dia de estanóis/esteróis reduz entre $6 \%$ e $15 \%$ o LDL-C (A2, B1).

\section{Proteína de soja}

- Alta ingestão de proteína de soja causa pequena redução do LDL-C, especialmente quando em substituição a gorduras de origem animal (A2, B2).

8. Ácidos graxos $\omega-3$

- Mecanismos pelos quais os ácidos graxos $\omega-3$ reduzem os eventos coronarianos não são totalmente elucidados e podem ser múltiplos. Evidências de estudos clínicos em prevenção secundária sugerem que altas doses de $\omega-3$ reduzem o risco de evento coronariano e mortalidade (A2, C2).

\section{Vitaminas}

- Não há estudos randomizados e controlados que mostrem evidências para o fato de que a diminuição dos níveis de homocisteína com a ingestão de B12, B6 e ácido fólico reduz o risco cardiovascular.

\section{Antioxidantes}

- Estresse oxidativo das LDL está envolvido na aterogênese; entretanto, até o momento, os estudos clínicos não demonstraram que a suplementação da dieta com antioxidantes reduza o risco cardiovascular (A2).

As tabelas 2 e 3 mostram as recomendações nutricionais do ATP-III, para a adequação da quantidade e do tipo de gorduras na dieta. 
Tabela 2. Recomendações nutricionais do ATP-III

\begin{tabular}{ll}
\hline Componente & Recomendação \\
\hline $\begin{array}{l}\text { Nutrientes que elevam LDL-C } \\
\text { Ácidos graxos saturados* } \\
\text { Colesterol alimentar }\end{array}$ & $<7 \%$ do total do VCT \\
Opções terapêuticas para a redução do LDL-C & $<200 \mathrm{mg} /$ dia \\
Estanóis/esteróis & $2 \mathrm{~g} /$ dia \\
Aumento da ingestão de fibras solúveis & $10-25 \mathrm{~g} /$ dia \\
Total de calorias & Ingestão calórica ajustada para \\
& manutenção de peso desejado \\
& e prevenção de ganho ponderal \\
Atividade física & Inclusão de exercício \\
& moderado que gaste no \\
& mínimo 200 kcal/dia \\
\hline
\end{tabular}

* Baixa ingestão de gordura trans.

VCT: valor calórico total.

\begin{tabular}{ll}
\hline \multicolumn{2}{l}{ Tabela 3. Recomendações de macronutrientes segundo o ATP-III } \\
\hline Componente & Recomendação \\
\hline Gordura poli-insaturada & Até 10\% do VCT \\
Gordura monoinsaturada & Até 20\% do VCT \\
Gordura total & $25-35 \%$ do VCT \\
Carboidratos $^{\star \star}$ & $50-60 \%$ do VCT* \\
Fibras totais & $20-30$ g/dia \\
Proteínas & Aproximadamente 15\% do VCT
\end{tabular}

* 0 ATP III permite 0 aumento de gordura até $35 \%$ do VCT e redução de carboidratos para 50\% para indivíduos portadores de síndrome metabólica. 0 aumento da ingestão de gordura deve ocorrer na forma de ácidos graxos poli-insaturados e monoinsaturados.

** Carboidratos complexos, especialmente grãos integrais, frutas e vegetais.

Fonte: National Cholesterol Education Program - ATP III, 2003.

VCT: valor calórico total

Declaração: os autores declaram não haver conflitos de interesse científico neste estudo.

\section{REFERÊNCIAS}

1. The World Health Report 2004. Global strategy on diet, physical activity, and health. Geneva: World Health Organization; 2004.

2. Ordovas JM. Diet-heart hypothesis: will diversity bring reconciliation? Am J Clin Nutr. 2005;82(5):919-20.

3. Howard BV, Van Horn L, Hsia J, Manson JE, Stefanick ML, Wassertheil-Smoller S, et al. Low-fat dietary pattern and risk of cardiovascular disease: the Women's Health Initiative Randomized Controlled Dietary Modification Trial. JAMA. 2006;295(6):655-66.

4. de Lorgeril M, Salen P. The Mediterranean-style diet for the prevention of cardiovascular diseases. Public Health Nutr. 2006;9(1A):118-23.

5. The Diabetes Prevention Program. Design and methods for a clinical trial in the prevention of type 2 diabetes. Diabetes Care. 1999;22(4):623-34.

6. Lindström J, Louheranta A, Mannelin M, Rastas M, Salminen V, Eriksson J, et al; Finnish Diabetes Prevention Study Group. The Finnish Diabetes Prevention Study (DPS): Lifestyle intervention and 3-year results on diet and physical activity. Diabetes Care. 2003;26(12):3230-6.
7. Iqbal R, Anand S, Ounpuu S, Islam S, Zhang X, Rangarajan S, et al. Dietary Patterns and the Risk of Acute Myocardial Infarction in 52 Countries Results of the INTERHEART Study. Circulation. 2008;118(19):1929-37.

8. Mahley RW, Huang Y. Atherogenic remnant lipoproteins: role for proteoglycans in trapping, transferring, and internalizing. J Clin Invest. 2007;117(1):94-8.

9. Lookene A, Zhang L, Hultin M, Olivecrona G. Rapid subunit exchange in dimeric lipoprotein lipase and properties of the inactive monomer. J Biol Chem. 2004;279(48):49964-72.

10. Rader DJ, Jaye M. Endothelial lipase: a new member of the triglyceride lipase gene family. Curr Opin Lipidol. 2000;11(2):141-7.

11. Patel MD, Thompson PD. Phytosterols and vascular disease. Atherosclerosis. 2006;186(1):12-9.

12. Yu L, Hammer RE, Li-Hawkins J, Von Bergmann K, Lutjohann D, Cohen JC, et al. Disruption of Abcg5 and Abcg8 in mice reveals their crucial role in biliary cholesterol secretion. Proc Natl Acad Sci USA. 2002;99(25):16237-42.

13. Mok HY, von Bergmann K, Grundy SM. Effects of continuous and intermittent feeding on biliary lipid outputs in man: application for measurements of intestinal absorption of cholesterol and bile acids. J Lipid Res. 1979;20(3):389-98.

14. Miettinen TA, Gylling $H$, Vanhanen $H$. Serum cholesterol response to dietary cholesterol and apoprotein $\mathrm{E}$ phenotype. Lancet. 1988;26;2(8622):1261.

15. Asakura L, Lottenberg AM, Neves MQ, Nunes VS, Rocha JC, Passarelli $\mathrm{M}$, et al. Dietary medium-chain triacylglycerol prevents the postprandial rise of plasma triacylglycerols but induces hypercholesterolemia in primary hypertriglyceridemic subjects. Am J Clin Nutr. 2000;71(3):701-5.

16. Bonanome A, Grundy SM. Effect of dietary stearic acid on plasma cholesterol and lipoprotein levels. N Engl J Med. 1988;318(19):1244-8.

17. Grundy SM, Vega GL. Plasma cholesterol responsiveness to saturated faty acids. Am J Clin Nutr. 1988;47(5):822-4.

18. Bennett AJ, Billett MA, Saler AM, Mangiapane EH, Bruce JS, Anderton $\mathrm{KL}$, et al. Modulation of hepatic apolipoprotein $B$, 3-hydroxy-3-methyglutaryl-CoA reductase and low-density lipoprotein receptor mRNA and plasma lipoprotein concentrations by defined dietary fats. Biochem J. 1995;311:167-73.

19. Nicolosi RJ, Stucchi AF, Kowala MC, Hennessy LK, Hegsted DM, Schaeffer E. Effect of dietary fat saturation and cholesterol on LDL composition and metabolism. Arteriosclerosis. 1990;10(1):119-28.

20. Jackson KG, Maitin V, Leake DS, Yaqoob P, Williams CM. Saturated fat-induced changes in Sf 60-400 particle composition reduces uptake of LDL by HepG2 cells. J Lipid Res. 2006;47(2):393-403.

21. Lee JY, CarrTP. Dietary fatty acids regulate acyl-CoA: cholesterol acyltransferase and cytosolic cholesteryl ester hydrolase in hamsters. J Nutr. 2004;134(12):3239-44.

22. Grundy SM. Influence of stearic acid on cholesterol metabolism relative to other long-chain fatty acids. Am J Clin Nutr. 1994;60(suppl):986S-990S.

23. Spritz N, Mishkel MA. Effects of dietary fats on plasma lipids and lipoproteins: and hyphotesis for the lipid-lowering effect of unsaturated fatty acids. J Clin Invest. 1969;48(1):78-86.

24. Keys A, Anderson JT, Grande F. Serum cholesterol response to changes in the diet IV. Particular saturated fatty acids in the diet. Metabolism. 1965;14:776-87.

25. Rioux V, Lemarchal P, Legrand P. Myristic acid, unlike palmitic acid, is rapidly metabolized in cultured rat hepatocytes. J Nutr Biochem. 2000;11(4):198-207. 
26. Nestel PJ. Effects of dairy fats within different foods on plasma lipids. J Am Coll Nutr. 2008;27(6):735S-40S.

27. Pietinen P, Vartiainen E, Seppanen R, Aro A, Puska P. Changes in diet in Finland from 1972 to 1992: impact on coronary heart disease risk. Prev Med. 1996;25(3):243-50.

28. Hu FB, Stampfer MJ, Manson JE, Rimm E, Colditz GA, Rosner $\mathrm{BA}$, et al. Dietary fat intake and the risk of coronary heart disease in women. N Engl J Med. 1997;337(21):1491-9.

29. Tripodi A, Loria P, Dilengite MA, Carulli N. Effect of fish oil and coconut oil diet on the LDL receptor activity of rat liver plasma membranes. Biochim Biophys Acta. 1991;1083(3):298-304.

30. Fernandez ML, McNamar DJ. Dietary fat-mediated changes in hepatic apoprotein $B / E$ receptor in the guinea pig: effect of polyunsaturated, monounsaturated, and saturated fat. Metabolism. 1989;38(11):1094-102.

31. Yu-Poth S, Yin D, Kris-Etherton PM, Zhao G, Etherton TD. Long-chain polyunsaturated fatty acids upregulate LDL receptor protein expression in fibroblasts and HepG2 cells. J Nutr. 2005;135(11):2541-5.

32. Lottenberg AM, Nunes VS, Lottenberg SA, Shimabukuro AF, Carrilho AJ, et al. Plasma cholesteryl ester synthesis, cholesteryl ester transfer protein concentration and activity in hypercholesterolemic women: effects of the degree of saturation of dietary fatty acids in the fasting and postprandial states. Atherosclerosis. 1996;126(2):265-75.

33. Pan $\mathrm{M}$, Cederbaum Al, Zhang YL, Ginsberg HN, Williams KJ, Fisher EA. Lipid peroxidation and oxidant stress regulate hepatic apolipoprotein B degradation and VLDL production. J Clin Invest. 2004;113(9):1277-87.

34. Hannah VC, Ou J, Luong A, Goldstein JL, Brown MS. Unsaturated fatty acids down-regulate srebp isoforms $1 \mathrm{a}$ and $1 \mathrm{c}$ by two mechanisms in HEK-293 cells. J Biol Chem. 2001;276(6):4365-72.

35. Lichtenstein AH, Ausman LM, Carrasco W, Jenner JL, Ordovas JM, Schaefer EJ. Hypercholesterolemic effect of dietary cholesterol in diets enriched in polyunsaturated and saturated fat. Arterioscler. Thromb. 1994;14(1):168-75.

36. Louheranta AM, Porkkala-Sarataho EK, Nyyssonen MK, Salonen RM, Salonen JT. Linoleic acid intake and susceptibility of very-low-density and low-density lipoproteins to oxidation in men. Am J Clin Nutr. 1996;63(5):698-703.

37. Harris WS, Mozaffarian D, Rimm E, Kris-Etherton P, Rudel LL, Appel LJ, et al. Omega- 6 fatty acids and risk for cardiovascular disease: a science advisory from the American Heart Association Nutrition Subcommittee of the Council on Nutrition, Physical Activity, and Metabolism; Council on Cardiovascular Nursing; and Council on Epidemiology and Prevention. Circulation. 2009;119(6):902-7.

38. Reaven PD, Grasse BJ, Tribble DL. Effect of linoleate-enriched and oleate-enriched diets in combination with $\alpha$-tocopherol on the susceptibility of LDL and LDL subfractions to oxidative modification in humans. Arterioscler. Thromb.1994;14(4):557-66.

39. Grundy SM. Multifactorial etiology of hypercholesterolemia. Implications for prevention of coronary heart disease. ArteriosclerThromb. 1991;11:1619-25.

40. Jones PJH, Lichtenstein AH, Schaefer EJ, Namchuk GL. Effect of dietary fat selection on plasma cholesterol synthesis in older, moderately hypercholesterolemic humans. Arterioscl Thromb. 1994;14(4):542-8.

41. Esposito K, Giugliano D. Mediterranean dietary patterns and chronic diseases. Am J Clin Nutr. 2008;88(4):1179-80.

42. Sommerfeld M. Trans unsaturated fatty acids in natural products and processed foods. Prog Lipid Res. 1983:22(3):221-33.

43. Matthan NR, Welty FK, Barrett PH, Harausz C, Dolnikowski GG, Parks JS, et al. Dietary hydrogenated fat increases high-density lipoprotein apoA-I catabolism and decreases low-density lipoprotein apoB-100 catabolism in hypercholesterolemic women. ArteriosclerThromb Vasc Biol. 2004;24(6):1092-7.

44. Buonacorso V, Nakandakare ER, Nunes VS, Passarelli M, Quintão EC, Lottenberg AM. Macrophage cholesterol efflux elicited by human total plasma and by HDL subfractions is not affected by different types of dietary fatty acids. Am J Clin Nutr. 2007;86(5):1270-7.

45. Matthan NR, Cianflone K, Lichtenstein AH, Ausman LM, Jauhiainen $M$, Jones PJ. Hydrogenated fat consumption affects acylation-stimulating protein levels and cholesterol esterification rates in moderately hypercholesterolemic women. J Lipid Res. 2001;42(11):1841-8.

46. Zapolska-Downar D, Kosmider A, Naruszewicz M. Trans fatty acids induce apoptosis in human endothelial cells. J Physiol Pharmacol. 2005;56(4):611-25.

47. Iso H, Kobayashi M, Ishihara J, Sasaki S, Okada K, Kita Y, et al; JPHC Study Group. Intake of fish and n3 fatty acids and risk of coronary heart disease among Japanese: the Japan Public Health Center-Based (JPHC) Study Cohort I. Circulation. 2006;113(2):195-202.

48. Rustan AC, Nossen JO, Christiansen EN, Drevon CA. Eicosapentaenoic acid reduces hepatic synthesis and secretion of triacylglycerol by decreasing the activity of acylcoenzyme A:1,2-diacylglycerolacyltransferase. J Lipid Res. 1988;29(11):1417-26.

49. Lottenberg AM, Oliveira HC, Nakandakare ER, Quintao EC. Effect of dietary fish oil on the rate of very low density lipoprotein triacylglycerol formation and on the metabolism of chylomicrons. Lipids.1992;27(5):326-30.

50. Jump DB. n-3 polyunsaturated fatty acid regulation of hepatic gene transcription. Curr Opin Lipidol. 2008;19(3):242-7.

51. Sampath $\mathrm{H}, \mathrm{Ntambi}$ JM. Polyunsaturated fatty acid regulation of genes of lipid metabolism. Annu Rev Nutr. 2005;25:317-40.

52. Rodriguez-Cruz M, Tovar AR, del Prado M, Torres N. Molecular mechanisms of action and health benefits of polyunsaturated fatty acids. Rev Invest Clin. 2005;57(3):457-72.

53. Hartweg J, Farmer AJ, Holman RR, Neil A. Potential impact of omega-3 treatment on cardiovascular disease in type 2 diabetes. Curr Opin Lipidol. 2009;20(1):30-8.

54. Mozaffarian D, Ascherio A, Hu FB, Stampfer MJ, Willett WC, Siscovick DS, et al. Interplay between different polyunsaturated fatty acids and risk of coronary heart disease in men. Circulation. 2005;111(2):157-64.

55. de Lorgeril M, Salen P, Martin JL, Monjaud I, Delaye J, Mamelle N. Mediterranean diet, traditional risk factors, and the rate of cardiovascular complications after myocardial infarction: final report of the Lyon Diet Heart Study. Circulation. 1999;99(6):779-85.

56. Gruppo Italiano per lo Studio della Sopravvivenza nell'Infarto miocardico (GISSI). Dietary supplementation with n-3 polyunsaturated fatty acids and vitamin $\mathrm{E}$ after myocardial infarction: results of the GISSI-Prevenzione trial. Lancet. 1999;354(9177):447-55.

57. Griffin BA. How relevant is the ratio of dietary n- 6 to $n-3$ polyunsaturated fatty acids to cardiovascular disease risk? Evidence from the OPTILIP study. Curr Opin Lipidol. 2008;19(1):57-62.

58. von Bergmann K, Sudhop T, Lutjohann D. Cholesterol and plant sterol absorption: recent insights. Am J Cardiol. 2005;96(1A):10D-4D.

59. Thompson GR, Grundy SM. History and development of plant sterol and stanol esters for cholesterol-lowering purposes. Am J Cardiol. 2005;96(1A):3D-9D.

60. Law M. Plant sterol and stanol margarines and health. Br Med J. 2000;320:861-4.

61. Champe PC, Harvey RA. Metabolism of dietary lipids. In: Champe PC, Harvey RA. Lippincott's illustrated reviews: biochemistry, 2a edição, editora J. B. Lippincott Company, Filadelphia, PA, 1994. p. 163. 
62. Plat J, Mensink RP. Incresead intestinal abca1 expression contibutes to the decrease in cholesterol absorption after plant stanol consumption. The FASEB J. 2002;16(10):1248-523.

63. Lottenberg AMP, Nunes VS, Nakandakare ER, MCPherson R, Quintão ECR. The human cholesteryl ester transfer protein $1405 \mathrm{~V}$ polymorphism is associated with plasma cholesterol concentration and its reduction by dietary phytosterol esters. J Nutr. 2003;133(6):1800-5.

64. Hallikainen MA, Uusitupa MJ. Effects of 2 low-fat stanol estercontaining margarines on serum cholesterol concentrations as part of a low-fat diet in hypercholesterolemic subjects. Am J Clin Nutr. 1999;69(3):403-10.

65. Wellen KE, Hotamisligil GS. Inflammation, stress, and diabetes. J Clin Invest. 2005;115(5):1111-9.

66. Hotamisligil GS. Role of endoplasmic reticulum stress and cJun NH2-terminal kinase pathways in inflammation and origin of obesity and diabetes. Diabetes. 2005;54(Suppl 2):S73-8.

67. Coenen KR, Gruen ML, Chait A, Hasty AH. Diet-induced increases in adiposity, but not plasma lipids, promote macrophage infiltration into white adipose tissue. Diabetes. 2007;56(3):564-73.

68. Nappo F, Esposito K, Cioffi M, Giugliano G, Molinari AM, Paolisso $G$, et al. Postprandial endothelial activation in healthy subjects and in type 2 diabetic patients: role of fat and carbohydrate meals. J Am Coll Cardiol. 2002;39(7):1145-50.

69. Baer DJ, Judd JT, Clevidence BA, Tracy RP. Dietary fatty acids affect plasma markers of inflammation in healthy men fed controlled diets: a randomized cro s s over study. Am J Clin Nutr. 2004;79(6):969-73.

70. Lopez-Garcia E, Schulze MB, Meigs JB, Manson JE, Rifai N, Stampfer MJ, et al. Consumption of trans fatty acids is related to plasma biomarkers of inflammation and endothelial dysfunction. J Nutr. 2005;135(3):562-6.

71. Eckel RH, Borra S, Lichtenstein AH, Yin-Piazza SY. Trans FaConference Planning Group. Understanding the complexity of trans fatty acid reduction in the American diet: American Heart Association Trans Fat Conference 2006: report of the Trans Fat Conference Planning Group. Circulation. 2007;115(16):2231-46.

72. Garbarino J, Sturley SL. Saturated with fat: new perspectives on lipotoxicity. Curr Opin Clin Nutr Metab Care. 2009;12(2):110-6.

73. Third Report of the National Cholesterol Education Program (NCEP) expert panel on detection, evaluation, and treatment of high blood cholesterol in adults (Adult Treatment Panel III) final report. Circulation. 2002;106(25):3143-421. 